respectively. In patients with ILD, CT scan \& FVC were compared at baseline \& 12 months.

Results: 29 patients (seropositive 28 (RF/Anti CCP/BOTH+VE), seronegative 1) were given RTX for RA over a 2-year period of which 12 had CD19, CD20 \& IgG tested. Mean SDAI reduction from baseline to 6 months post treatment was $30 \%, 32 \%$ \& $14 \%$ while complete remission (SDAl<3.3) was attained in $100 \%$, $18 \%$ \& $20 \%$ in DMARD naïve, DMARD resistant \& ILD groups, respectively. CD19, CD20 \& IgG reduced from $18.6 \%, 18.4 \%$ \& $18.53 \mathrm{~g} / \mathrm{L}$ to $3.7 \%, 3.7 \%$ \& $9.7 \mathrm{~g} / \mathrm{L}$ respectively $\mathrm{FVC}$ improved from $62.4 \%$ to $67 \%$ at 12 . The percentage of patients with lung involvement $>20 \%$ reduced from $53.3 \%$ to $46.7 \%$. Flare was observed in one patient who received 500mg RTX. CD19, CD20 \& IgG levels increased from $7.9 \%, 8 \% \& 9.8 \mathrm{~g} / \mathrm{L}$ to $27 \%, 25 \% \& 13 \mathrm{~g} / \mathrm{L}$ respectively. 3 patients in the $1 \mathrm{~g}$ group were followed up at $12,18 \& 24$ months. In these patients there were no flares or worsening symptoms. 1 patient was double negative for RF \& Anti CCP and this patient did not attain clinical remission even after 2 doses of $1 \mathrm{~g}$ RTX.

Conclusion:

[1] Patients with early arthritis (diagnosis made within 1 year) and who were DMARD naïve had an excellent response to Rituximab.

[2] Complete remission was observed in more patients the $1 \mathrm{~g}$ compared to 500mg group.

[3] Reduction in CD19 \& CD20 was associated with significant reduction in the SDAl score.

[4] There was no significant reduction of CD19 \& CD20 with 500mg dose of Rituximab where either a partial remission or mild flare was observed.

[5] There was reduction in the lung involvement to less than $20 \%(C T)$ in few patients with $1 \mathrm{~g}$ dose.

[6] Double negative Rheumatoid arthritis poorly responded to Rituximab.

[7] The positive effects of $1 \mathrm{~g}$ Rituximab could be noted up to 24 months.

[8] Flare of RA was associated with significant increase in CD19 \& CD20.

Disclosure of Interests: None declared

DOI: 10.1136/annrheumdis-2021-eular.3794

\section{AB0236 DOWN-TITRATION STRATEGY OF TUMOR NECROSIS FACTOR-INHIBITOR AGENTS FOR RHEUMATOID ARTHRITIS IN TUNISIA}

K. Saadaoui ${ }^{1}$, H. Sahli ${ }^{1}$, S. Boussaid ${ }^{1}$, J. Samia ${ }^{1}$, R. Sonia ${ }^{1}$, C. Elhem ${ }^{1}$, E. Mohammed ${ }^{1}$ ' La Rabta Hospital, Rheumatology, Tunis, Tunisia

Background: Tumor necrosis factor (TNF) blocking agents are effective in treating rheumatoid arthritis, but they are associated with several adverse effects and high costs. Some studies have assessed the effectiveness of down-titration compared with continuation of standard dose.

Objectives: The aim of our study is to assess dose tapering in Tunisia.

Methods: A retrospective study including 170 rheumatoid arthritis patients treated by TNF blocker agent and with either low disease activity or remission (ACR/EULAR criteria). Two groups were compared, in the first group (G1) the interval of TNFi administration was extended, in the second group (G2) the standard dose and rhythm of administration were maintained.

Results: The TNFi tapering group (G1) included 96 persons whereas the group having the same drug administration rhythm (G2) included 74 case. The baseline age of the down-dosing drug group was $56.6 \pm 12.6$ years versus $52.9 \pm$ 11.6 years in the other group $(p=0.046)$ and the average disease duration were respectively $12.3 \pm 7.2$ years versus $11.2 \pm 6$ years $(p=0.346)$. Women represented $88.5 \%$ in $G 1$ versus $93 \%$ in $G 2$ ( $p=0.298$ ). Rheumatoid Factors and ACPA were positive respectively in $(85.5 \%$ versus $83.8 ; p=0.748)$ and (76.4\% versus $67.8 \% ; p=0.309$ ). Etanercept, adalimumab, certolizumab pegol and infliximab were respectively used in $84.4 \%, 9.4 \%, 4.2 \%$ and $2.1 \%$ cases (G1), whereas they were used in $48.6 \%, 16.2 \%, 27 \%$ and $8.1 \%$ cases in the second group (G2). In the TNFi down dosing group, methotrexate was associated to TNFi in $74 \%$ cases while $71.6 \%$ of patient received methotrexate in the standard rhythm of administration group $(p=0.734)$. Corticosteroids were used by $40.6 \%$ of patients in $\mathrm{G} 1$ vs. $56.8 \%$ of patients in $\mathrm{G} 2(\mathrm{p}=0.037)$. The average $\mathrm{DAS}_{28}$ at baseline was $5.91 \pm 0.81$ (G1) versus $5.95 \pm 0.80$ (G2) $(p=0.759)$. There was no statistically significant difference between the two groups for rates of TNFi withdrawal $(p=0.798)$. In fact, TNFi was interrupted due to inefficacy for 17 patients $(17.7 \%)$ in the down-dosing group versus 12 patients $(16.2 \%)$ in the other group.

Conclusion: Our study add evidence that TNFi drugs tapering could be equivalent to maintenance strategy. This could be beneficial to decrease the risk of adverse effect or reduce costs. Further studies are needed to confirm those results and identify patients who could benefit of TNFi administration rhythm step-down

Disclosure of Interests: None declared

DOI: 10.1136/annrheumdis-2021-eular.3804

\section{AB0237 INFECTIONS IN PATIENTS WITH RHEUMATOID ARTHRITIS TREATED WITH RITUXIMAB AND ANTI-TNF INHIBITOR}

N. Zehraoui ${ }^{1}$, R. Benaziez.Boutaleb ${ }^{1}$, H. Hafirassou ${ }^{1}$, F. Mechid ${ }^{1}$, N. Bahaz ${ }^{1}$, C. Makhloufi-Dahou ${ }^{1} .{ }^{1}$ Mohamed Lamine Debaghine University Hospital, Rheumatology, Algiers, Algeria

Background: Biological therapies have significantly improved the management of rheumatoid arthritis (RA). These molecules are very effective, but are known for their specific risks, especially infectious. It depends on several factors including the type of molecule used.

Objectives: The objective of our study is to compare the rate of infection in RA patients treated with rituximab and anti-TNF $\alpha$.

Methods: Prospective, observational, monocentric study. Were included RA patients (ACR / EULAR 2010 criteria) treated with rituximab and anti-TNF $\alpha$ (adalimumab, infliximab and Etanercept) after inadequate response to DMARDs Demographic characteristics, comorbidities, association with methotrexate and corticosteroids were collected and compared for each group.

The number, type and severity of the infections in both cases were noted. SPSS (Statistical Package for Social Science) was used for data analysis. Results: 40 RA patients treated with rituximab and 31 patients who received anti-TNF $\alpha$ were included

Patient characteristics and Comparison of rate of infection in RA patients between the two groups are summarized in Table 1

\section{Table 1.}

\begin{tabular}{lccc}
\hline Parameters & Rituximab & Anti-TNF $\alpha$ & $p$ \\
\hline Number of patients & 40 & 31 & \\
Average age (years) & $\mathbf{5 6 , 2 8}$ & 46,06 & 0,01 \\
Sexratio & 0,14 & 0,11 & 0,7 \\
Average duration of evolution (years) & 15,83 & 13,74 & 0,3 \\
Patients under corticosteroid (\%) & 97,5 & 87,1 & 0,08 \\
Average corticosteroid dose & 6,41 & $\mathbf{5 , 4 8}$ & 0,3 \\
patients under methotrexate (\%) & 37,5 & 45,2 & 0,5 \\
Diabetes (\%) & 20 & 16,1 & 0,7 \\
Patients with infection (\%) & 32,5 & $\mathbf{5 1 , 6}$ & 0,1 \\
Number of infections & 18 & 24 & 0,4 \\
Number of serious infections & 5 & 0 & 0,04 \\
\hline
\end{tabular}

Conclusion: The rate of infections in patients with RA treated with rituximab or anti-TNF was similar. However, the infections observed were more serious in patients with RA treated with rituximab

\section{REFERENCES:}

[1] Fabiola Atzeni MD PhD and al. Infections and Biological Therapy in Patients with Rheumatic Diseases. IMAJ . VOL 18. march-APRIL 2016.

[2] Huifeng Yun and al. Comparative Risk of Hospitalized Infection Associated with Biologic Agents in Rheumatoid Arthritis Patients Enrolled in Medicare. ARTHRITIS \& RHEUMATOLOGY. Vol. 68, No. 1, January 2016, pp 56-66.

[3] Manjari Lahiri and al. Risk of infection with biologic antirheumatic therapies in patients with rheumatoid arthritis. Best Practice \& Research Clinical Rheumatology (2015) 1-16.

Disclosure of Interests: None declared

DOI: 10.1136/annrheumdis-2021-eular.3854

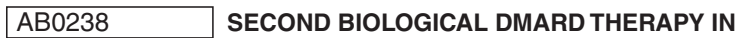 RHEUMATOID ARTHRITIS: A RETROSPECTIVE COHORT ANALYSIS}

K. Saadaoui ${ }^{1}$, H. Sahli ${ }^{1}$, S. Jemmali ${ }^{1}$, S. Boussaid ${ }^{1}$, S. Rekik ${ }^{1}$, E. Cheour ${ }^{1}$, M. Elleuch'. ' La Rabta Hospital, Rheumatology, Tunis, Tunisia

Background: The development of biologic disease modifying antirheumatic drugs (bDMARD) has dramatically improved the management of rheumatoid arthritis (RA). However, some patients did not respond or partially respond to biologic agents. Management of first bDMARD failure may involve another biotherapy. Objectives: The aim of our study is to assess the efficacy of second line biologic as well as survival rates of $2^{\text {nd }}$ line biotherapy in RA.

Methods: This is a retrospective study based on Tunisian data including 374 RA patients treated with biologic agent from 2014 and followed until December 2018 Results: Tumor necrosis factor inhibitor (TNFi) was the most prescribed class as first-line therapy with $86.4 \%$ patients (Etanercept: ETA 54\%; adalimumab: ADA 13.6\%; certolizumab pegol: CZP $12.8 \%$ and infliximab: IFX 5.9\%), IL-6 inhibitor (Tociluzimab: TCZ) and anti-CD 20 (Rituximab: RTX) were given respectively to $6.4 \%$ and $7.2 \%$ cases. The first biotherapy was discontinued for 146 patients (39\%). Of these, 79 patients (21.1\%) received a second bDMARD (mean age 52.6 \pm 11.8; sex ratio $=0.12$; ETA $17.7 \%$, ADA 7.6\%, CZP 41.8\%, IFX 1.3\%, TCZ $24.1 \%$ and RTX 7.6\%). Average $\mathrm{DAS}_{28}$ at second line biotherapy initiation was $5.93 \pm$ 
0.96. Overall survival rates of $2^{\text {nd }}$ line bDMARD at 12,24 and 36 months was respectively $91 \%, 76.4 \%$ and $72.1 \%$. Among the patients receiving second biologic agent, $30.4 \%$ patients ( 24 cases) achieved either low disease activity (LDA) or remission. On average 38 weeks [14 - 96] were needed to reach that therapeutic target. In fact, $27.8 \%$ of the TNFi vs. $40 \%$ of the non TNFi patients achieved LDA $(p=0.277)$. Second biotherapy was withdrawn in $16.7 \%$ of the cases of TNFi group vs. $20 \%$ of the non TNFi group ( $p=0.718$ ). Moreover, no significant difference has emerged between the TNFi and the non-TNFi patients when comparing time to biotherapy discontinuation (15.8 months vs. $20.9 ; p=0.11$ )

Conclusion: In our study, no significant difference was found between TNFi and non-TNFi switcher in RA. But, treatment strategy after first bDMARD failure is still controversial. Further studies have to be done to get the most beneficial strategy in RA.

Disclosure of Interests: None declared

DOI: 10.1136/annrheumdis-2021-eular.3871

\section{AB0239 PERSISTENCE TO BIOLOGICAL DMARDS TNF INHIBITORS VS BIOLOGICAL DMARDS NOTNF INHIBITORS AFTER FAILURE TO SYNTHETIC CONVENTIONAL DMARDS IN RA PATIENTS TREATED IN STANDARD CLINICAL PRACTICE}

B. Hernández-Cruz ${ }^{1}$, P. Muñoz Reinoso ${ }^{2}$, I. García Hernández ${ }^{3}$, G. Jurado Quijano $^{3}$, L. Fernández de la Fuente Bursón ${ }^{3}$, I. M. Fernández-Maeztu

Palacín $^{3}$, A. Fernández Reboul Fernández ${ }^{3}$, D. Ruiz-Montesinos ${ }^{3}$, J. J. Pérez Venegas ${ }^{3} .{ }^{1}$ Hospital Universitario Virgen Macarena, Rheumatology, Seville, Spain; ${ }^{2}$ Hospital Universitario Virgen Macarena, Rheumatologyy, Sevilla, Spain; ${ }^{3}$ Hospital Universitario Virgen Macarena, Rheumatology, Sevilla, Spain

Background: There are no RA response predictors for our patients. The decision to initiate a first biological depends on multiple factors such as rheumatologist experience, clinical characteristics of the patient and health system. What is clear is that the best strategy is T2T.

Objectives: To know the clinical characteristics and persistence of the first biological DMARD in patients receiving bDMARDS TNF inhibitors vs DMARDs aimed at other targets.

Methods: A observational cohort of adult RA patients (ACR/EULAR 2010) in a rheumatology department of a third-level university hospital. All patients were treated with a first bDMARD marketed in Spain, from 2010 to December 2020 and prescribed according to product data sheet. Biological drugs were divided into TNF inhibitors drugs (adalimumab, etanercept, infliximab, golimumab, certolizumab) and Other targets (abatacept, rituximab, sarilumab, tocilizumab). Clinical data, duration of treatment and EULAR response were collected from each patient. The data were analyzed with descriptive, bivariate statistics and survival analysis adjusted for age, sex, FR, erosions and duration of the disease.

Results: Data were collected from 332 patients (table 1). Patients treated with other target bDMARDs were mostly female, with higher activity, shorter disease duration, and treated without MTX.b Survival graphs showed that regardless of the target chosen as fist bDMARD, EULAR response rates and persistence to the drug were similar.

Table 1.

\begin{tabular}{lcccc}
\hline Variable & $\begin{array}{c}\text { TNF inhibitors } \\
\mathrm{n}=194\end{array}$ & $\begin{array}{c}\text { Other targets } \\
\mathrm{n}=138\end{array}$ & $\begin{array}{c}\text { Total } \\
\mathrm{n}=332\end{array}$ & $\mathrm{p}$ \\
\hline & $\mathrm{n}(\%)$ & $\mathrm{n}(\%)$ & $\mathrm{n}(\%)$ & 0.02 \\
\hline Female & $142(73)$ & $115(83)$ & $257(77)$ & 0.2 \\
FR + & $163(82)$ & $121(88)$ & $284(86)$ & 0.6 \\
ACPA + & $125(63)$ & $84(61)$ & $209(63)$ & 0.9 \\
Erosions & $177(89)$ & $80(58)$ & $257(77)$ & 0.01 \\
Concomitant MTX & $153(77)$ & $62(47)$ & $215(65)$ & 0.003 \\
EULAR response & & & & \\
Good & $103(77)$ & $67(71)$ & $170(75)$ & 0.2 \\
Moderate & $24(18)$ & $16(17)$ & $40(17)$ & \\
No & $7(5)$ & $11(11)$ & $18(8)$ & \\
Age (years) & Mean $\pm \mathrm{SD}$ & Mean $\pm \mathrm{SD}$ & $\mathrm{Mean} \pm \mathrm{SD}$ & \\
Evolution of RA (years) & $55.7 \pm 13.3$ & $57.6 \pm 11.9$ & $56.5 \pm 12.7$ & 0.1 \\
Persistence (months) & $9.6 \pm 10.2$ & $7.5 \pm 7.5$ & $8.7 \pm 9.2$ & 0.04 \\
DAS28VSG4V basal & $19.3 \pm 20.5$ & $16.07 \pm 15.11$ & $17.5 \pm 18.5$ & 0.04 \\
DAS28VSG4V final & $5.02 \pm 1.5$ & $5.59 \pm 1.03$ & $5.25 \pm 1.3$ & 0.001 \\
\hline
\end{tabular}

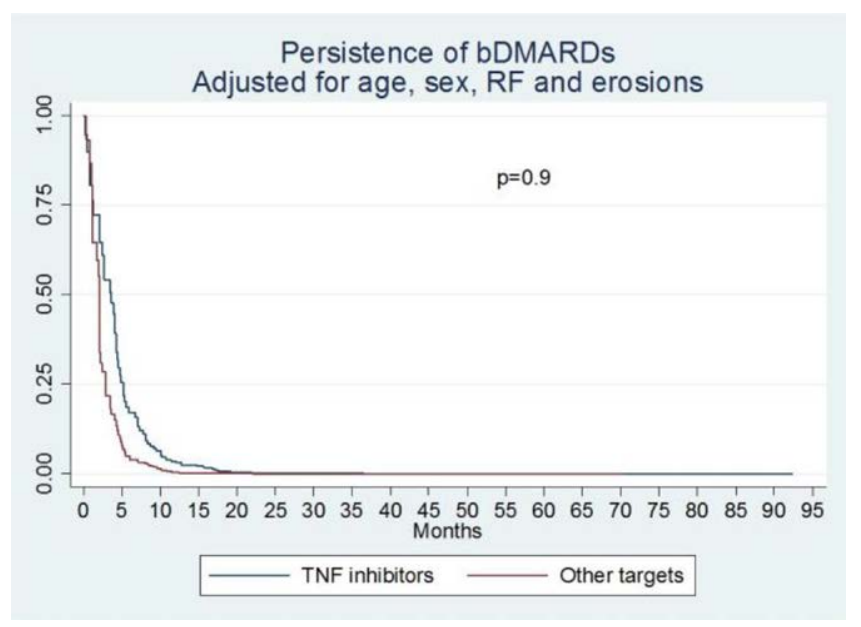

Conclusion: Patients receiving Anti-TNF vs bDMARD with other mechanisms of action have clinical differences. However, the response and persistence to the drug are similar, perhaps due to the implementation of the correct T2T strategy.

Disclosure of Interests: None declared

DOI: 10.1136/annrheumdis-2021-eular.3920

\section{AB0240 1 PREDICTORS OF RESPONSE TO BIOLOGIC AGENTS IN RHEUMATOID ARTHRITIS}

K. Saadaoui ${ }^{1}$, H. Sahli ${ }^{1}$, S. Jemmali ${ }^{1}$, S. Boussaid ${ }^{1}$, S. Rekik ${ }^{1}$, E. Cheour ${ }^{1}$, M. Elleuch'. 'La Rabta Hospital, Rheumatology, Tunis, Tunisia

Background: In rheumatoid arthritis (RA), the 'treat-to-target' therapeutic approach imposes rigorous control of disease activity. Although biological agents have been shown to be effective, these therapies fail sometimes to achieve therapeutic goals.

Objectives: In this study we tried to determine predictive factors of good therapeutic response to biologic disease-modifying antirheumatic drugs (bDMARD).

Methods: This is a retrospective study including 374 Tunisian patients who received their first biotherapy between 2014 and 2016. Categorical variables were reported in numbers and percentages, while quantitative variables were expressed by mean with standard deviations. The univariate analysis was performed using the student t-test or the Chi2 test. Multivariate analysis was performed by binary logistic regression.

Results: Average age of our cohort was $55 \pm 12.5$ years with a female predominance of $87.2 \%$. The average duration of RA was $11.7 \pm 6.7$ years. Rheumatoid factors were positive in $79 \%$ and ACPA were positive in $72 \%$ of cases. After the introduction of biotherapy, low disease activity (LDA) or remission was achieved in $55 \%$ of cases (206 patients).

No statistically significant difference between biotherapy responder and non-responder groups for age (55.7 vs. 54.7 years; $p=0.44)$, gender (Female: $86.5 \%$ vs. $88.7 \% ; p=0.08$ ) and disease duration (12 years vs. 11.4 years; $p=$ $0.41)$. A significant difference between the two groups was found for the positivity of rheumatoid factors $(76.4 \%$ vs. $88.9 \% ; p=0.004)$, methotrexate's association (65\% vs. $53.4 \%$; $p=0.02)$ and corticosteroids' use (50\% vs. $66.5 \%$; $<0.001)$.

Positive predictive factors of remission or LDA by biotherapy were female sex (Odds Ratio $=2.2 ; p=0.026$ ), presence of rheumatoid factors (Odds Ratio = $2.64 ; p=0.001$ ), association with methotrexate (Odds Ratio $=1.69 ; p=0.028$ ). Whereas, corticosteroid use $(O R=0.41 ; p<10-3)$ was a negative predictor of disease control by bDMARDs.

Conclusion: Achieving LDA low level or even remission is currently achievable with biological treatments. Certain factors need to be studied in order to optimize RA treatment and adapt the right bDMARD for each patient.

Disclosure of Interests: None declared

DOI: 10.1136/annrheumdis-2021-eular.3928 